\title{
Breakdown of the coral-algae symbiosis: towards formalising a linkage between warm-water bleaching thresholds and the growth rate of the intracellular zooxanthellae
}

\author{
S. A. Wooldridge \\ Australian Institute of Marine Science, PMB\#3 Townsville MC, 4810 Australia \\ Correspondence to: S. A. Wooldridge (s.wooldridge@aims.gov.au)
}

Received: 3 July 2012 - Published in Biogeosciences Discuss.: 5 July 2012

Revised: 15 February 2013 - Accepted: 23 February 2013 - Published: 12 March 2013

\begin{abstract}
Impairment of the photosynthetic machinery of the algal endosymbiont ("zooxanthellae") is the proximal driver of the thermal breakdown of the coral-algae symbiosis ("coral bleaching"). Yet, the initial site of damage, and early dynamics of the impairment are still not well resolved. In this perspective essay, I consider further a recent hypothesis which proposes an energetic disruption to the carbon-concentrating mechanisms (CCMs) of the coral host, and the resultant onset of $\mathrm{CO}_{2}$-limitation within the photosynthetic "dark reactions" as a unifying cellular mechanism. The hypothesis identifies the enhanced retention of photosynthetic carbon for zooxanthellae (re)growth following an initial irradiance-driven expulsion event as a strong contributing cause of the energetic disruption. If true, then it implies that the onset of the bleaching syndrome and setting of upper thermal bleaching limits are emergent attributes of the coral symbiosis that are ultimately underpinned by the characteristic growth profile of the intracellular zooxanthellae; which is known to depend not just on temperature, but also external (seawater) nutrient availability and zooxanthellae genotype. Here, I review this proposed bleaching linkage at a variety of observational scales, and find it to be parsimonious with the available evidence. Future experiments are suggested that can more formally test the linkage. If correct, the new cellular model delivers a valuable new perspective to consider the future prospects of the coral symbiosis in an era of rapid environmental change, including: (i) the underpinning mechanics (and biological significance) of observed changes in resident zooxanthellae genotypes, and (ii) the now crucial importance of reef water quality in co-determining thermal bleaching resistance.
\end{abstract}

\section{Introduction}

The high productivity and extensive accretion of skeletal carbonate by shallow-water tropical reef ecosystems is testament to the evolutionary success of the symbiotic association between scleractinian ("reef-building") corals and unicellular dinoflagellate algae of the genus Symbiodinium ("zooxanthellae") (Fig. 1) (Veron, 1995; Stanley, 2006). Within this association, often mixed consortia of zooxanthellae types live within the coral tissues in extremely high densities (greater than $10^{6} \mathrm{~cm}^{-2}$ ) and perform intensive photosynthesis (Fig. 2a). Under the optimal conditions provided by nutrient-poor tropical waters, the vast majority $(>90 \%)$ of this assimilated organic carbon ("photosynthate") is typically translocated to the coral, contributing substantially to its carbon and energy needs (Trench, 1993; Yellowlees et al., 2008). However, this "producer-within-consumer" arrangement is very sensitive to any above average increase in irradiance and/or temperature, and exposure of coral communities to temperatures as little as $1-2{ }^{\circ} \mathrm{C}$ above the average summer maximum can lead to breakdown of the symbiosis. This breakdown results in expulsion of the algal partner causing the phenomenon known as coral "bleaching" (reviewed by Brown, 1997). When bleaching is severe, and the symbiosis is unable to re-establish itself, the coral host dies.

Impairment of the photosynthetic machinery of the zooxanthellae is the well-accepted proximal driver of the thermal bleaching response. Indeed, photoinhibition of photosynthetic electron transport, the consequent photodamage to photosystem II (PSII), and the resultant excess production of damaging reactive oxygen species (ROS) are distinctive "signatures" of the thermal bleaching response (Lesser, 


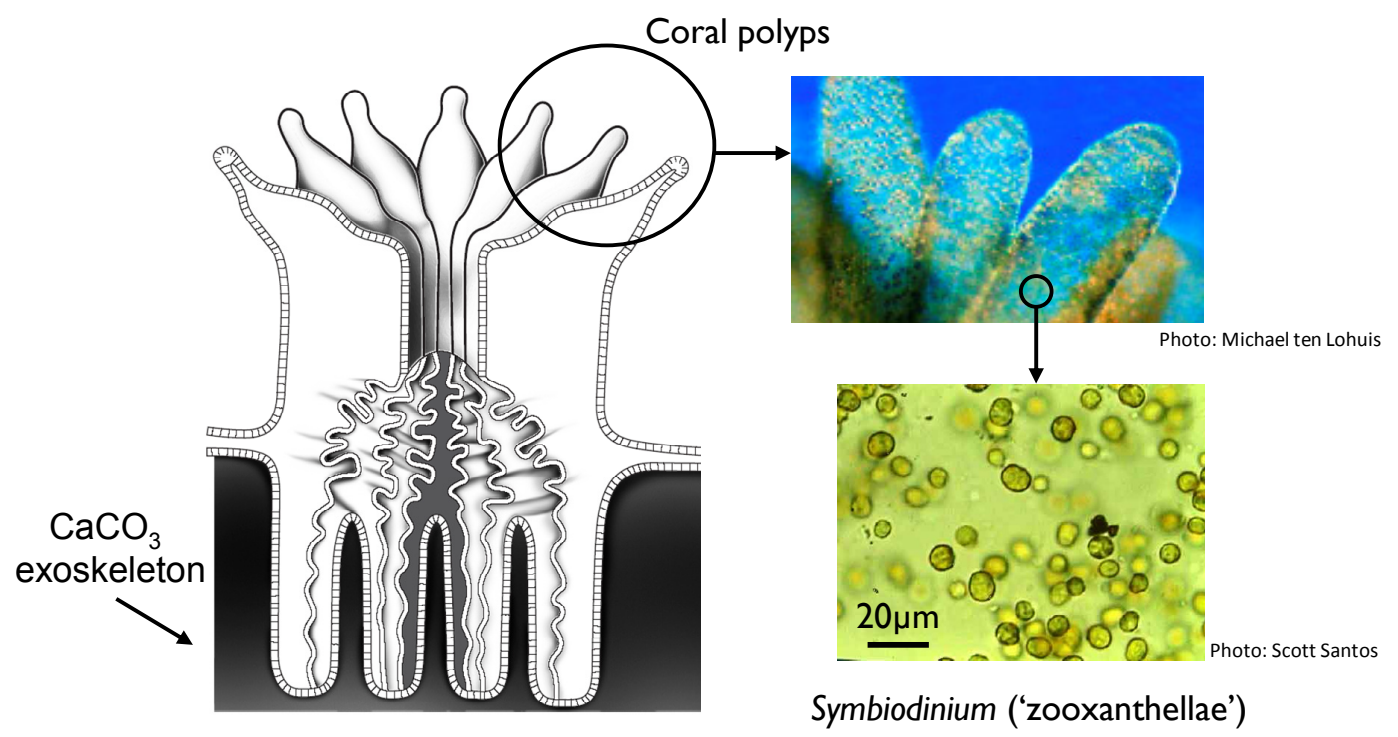

Fig. 1. A reef coral is a symbiotic association between an animal (the host) and unicellular dinoflagellate algae (the symbiont). Within this association, the dinoflagellate algae of the genus Symbiodinium ("zooxanthellae") reside within the gastrodermal cells of the coral host. Originally it was believed that only a single zooxanthellae species engaged in the symbiotic relationship with corals. However, it is now understood that Symbiodinium are genetically diverse: consisting of eight major divergent lineages (clades A-H), with each clade containing multiple subclade genotypes (herein referred to as type(s)) (reviewed by Baker, 2003). The genetically diverse zooxanthellae types differ in their phenotypic response (e.g. growth rate, photosynthetic yield) to external conditions, particularly light and temperature regimes (Kinzie et al., 2001; Rowan, 2004). Modern genomic techniques demonstrate that many coral species can associate with multiple zooxanthellae types (often simultaneously), though the extent to which this flexibility is available to all symbiotic corals remains uncertain (Baker, 2003; Goulet, 2006).

1996; Warner et al., 1999; Jones and Hoegh-Guldberg, 2001). However, it is yet to be determined whether this detrimental cellular cascade within the photosynthetic "light reactions" is the initial trigger, or just a secondary consequence of other processes occurring within the zooxanthellae or the host cells (reviewed by Smith et al., 2005). The fact that the majority of expelled zooxanthellae from thermally stressed corals remain photosynthetically competent (Ralph et al., 2001; Bhagooli and Hidaka, 2004) highlights the possibility that it may be a secondary response. Similarly, there is a growing body of evidence to indicate that dysfunction within the "dark reactions" of photosynthesis often precedes the photoinhibition bleaching response (Jones et al., 1998; Buxton et al., 2012).

In an effort to reconcile the discordant observations, Wooldridge (2009a) outlined how the "photoinhibition model" of coral bleaching can be extended to include the possibility that the bleaching response is initially triggered by a failure of the coral host to maintain a sufficient supply of $\mathrm{CO}_{2}$ for its endosymbiont partner, particularly during periods of excess solar radiation when the photosynthetic demand for $\mathrm{CO}_{2}$ is maximal. Theoretical considerations do permit $\mathrm{CO}_{2}$ (sink) limitation within the "dark reactions" of photosynthesis to be proposed as a potential trigger for the classic bleaching sequence of photoinhibition, oxidative damage and zooxanthellae expulsion (Fig. 2b; Wooldridge, 2009a). In this case: (i) lack of $\mathrm{CO}_{2}$ substrate required for the "dark reactions" can reduce the rate of consumption of the products of photosynthetic electron transport (ATP (adenosine triphosphate) and NADPH (nicotinamide adenine dinucleotide phosphate)), subsequently causing the photosynthetic electron transport components of the "light reactions" to become blocked (Takahashi and Murata, 2006); (ii) continued funnelling of excitation energy into the over-reduced electron transport chain can then trigger the onset of photoinhibition (Jones and Hoegh-Guldberg, 2001), damage essential photosynthetic components (principally PSII), and generate damaging ROS (Lesser, 1996; Warner et al., 1999); and (iii) the excess production of ROS beyond the antioxidant defence strategies of the coral host (and zooxanthellae) can been linked to the host-cell necrosis and detachment that underpins zooxanthellae expulsion (Gates et al., 1992; Dunn et al., 2002).

Wooldridge (2009a) identified an energy-dependent disruption to the carbon-concentrating mechanisms (CCMs) of the coral host as a likely trigger-point for the onset of $\mathrm{CO}_{2}$-limitation (and resultant expulsion). If the CCMs were to become disrupted, especially during periods of high (irradiance-driven) photosynthetic demand for $\mathrm{CO}_{2}$, then the likelihood of the zooxanthellae experiencing $\mathrm{CO}_{2}$ limitation would be real, and the consequence would be the classical symptoms of coral bleaching (Fig. 2b). This 

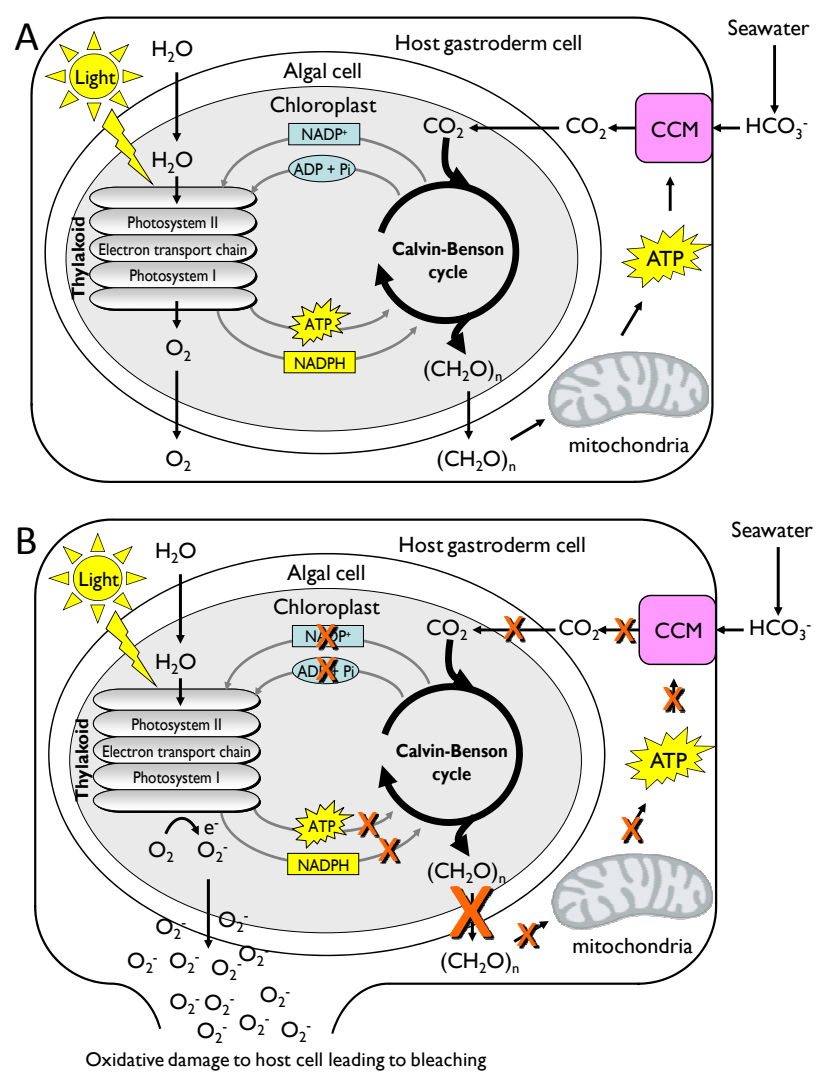

Fig. 2. The coral-algae symbiosis. (A) Conceptual overview of the internal carbon cycling that is maintained by the coralzooxanthellae symbiosis (after Wooldridge, 2009a). Zooxanthellae photosynthesis takes place within the algae chloroplast, with the "light reactions" occurring in the thylakoid membranes, and the "dark reactions" (Calvin-Benson cycle) in the stroma. The vast majority $(>90 \%)$ of the assimilated photosynthates $\left(\left(\mathrm{CH}_{2} \mathrm{O}\right)_{\mathrm{N}}\right)$ are typically transferred to the coral host. To ensure an adequate supply of $\mathrm{CO}_{2}$ for its zooxanthellae, the coral host maintains a range of active CCMs. The ATP needed to activate the CCMs is ultimately derived from the transferred photosynthates. (B) Should the flow of photosynthates from the zooxanthellae become disrupted, then the capacity of the coral host to energise the CCMs becomes limiting, leaving the dark reaction of photosynthesis vulnerable to $\mathrm{CO}_{2}$ (sink) limitation. With no means to turn over ATP and NADPH, the photosynthetic electron transport chain becomes blocked, which damages the light-sensitive photosystems and generates damaging reactive oxygen species that can trigger the onset of zooxanthellae expulsion (= bleaching)

vulnerability is reinforced by the fact that the ATP needed to activate the CCMs is ultimately derived from the transferred photosynthate of the zooxanthellae. For example, the quick release of energy-rich photosynthates (within $1 \mathrm{~min}$ of fixation; Trench, 1993) ensures rapid activation of implicated CCMs (Al-Horani et al., 2003). This reliance on photosynthate transfer to energise the CCMs ensures that zooxanthellae indirectly play a role in generating the $\mathrm{CO}_{2}$ that they require to maintain optimal photosynthesis. Therefore, should the flow of photosynthates from the zooxanthellae become disrupted then the ability of the coral host to energise the CCMs will be compromised. In turn, the zooxanthellae will be progressively exposed to a limiting supply of essential $\mathrm{CO}_{2}$ substrate, potentially compromising photosynthetic yields and reinforcing the diminished photosynthate flux. In this way, a weakening in the potential for autotrophy with respect to carbon can be understood to quickly compromise the stability of the symbiosis, especially during periods of high irradiance.

Although a number of negative feedback cycles come into play, Wooldridge (2009a, 2010) identified the retention of photosynthate for zooxanthellae (re)growth following an initial irradiance-driven expulsion event as the likely dominating feature of the energetic disruption to the host CCMs (summarised by Fig. 3). In essence, when a large number of zooxanthellae are expelled (per day) and then subsequently produced (per day), the increased respiratory cost of this population turnover is predicted to result in a negative autotrophic energy balance (i.e. photosynthesis : respiration $<1$ ); which in the absence of heterotrophic carbon input, progressively compromises the hosts cellular energy reserves. The implications of this suggestion are intriguing, since it implies that in natural settings, the onset of the bleaching syndrome and setting of upper thermal bleaching limits are emergent attributes of the coral symbiosis that are ultimately underpinned by the characteristic growth profile of the intracellular zooxanthellae; with excessive (re)growth potential equating with reduced thermotolerance. Since zooxanthellae growth rates have been extensively measured, and are known to display consistent variations depending not just on temperature (Kinzie et al., 2001; Strychar et al., 2004), but also external (seawater) nutrient availability (Hoegh-Guldberg, 1994; McGuire and Szmant, 1997) and Symbiodinium type (Kinzie et al., 2001; Fitt, 1985), it follows that there exists a wealth of information (at a variety of observational scales) with which to test the parsimony of the proposed bleaching linkage. The following essay provides a review of this evidence, and where possible, endeavours to provide insight into the design of future experiments that can more formally test the linkage.

\section{The coral-algae symbiosis: zooxanthellae cell proliferation}

Dinoflagellates have relatively slow rates of cell proliferation compared to other unicellular algae (Tang, 1996). This slow growth dynamic makes zooxanthellae particularly well suited to symbiotic relationships (Wong and Kwok, 2005). In its free-living state, zooxanthellae can exist as motile zoospore (Stat et al., 2006). However, once internalised in symbio, chemical signalling by the host arrests the zooxanthellae life cycle within a cell-dividing (vegetative) 


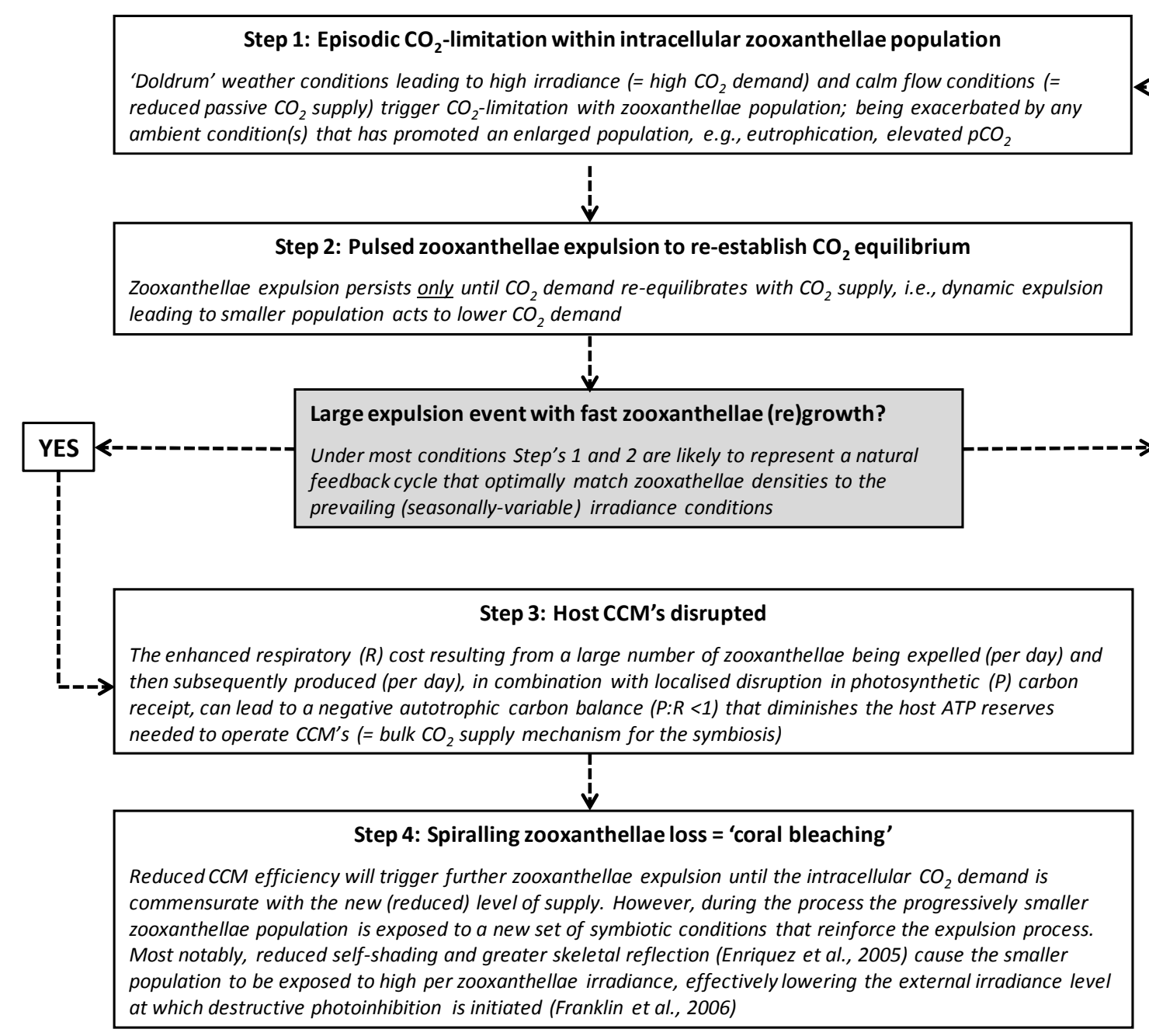

Fig. 3. Schematic process sequence for the proposed $\mathrm{CO}_{2}$-limitation coral bleaching model (after Wooldridge, 2009a).

non-motile state (Koike et al., 2004; Stat et al., 2006). The different zooxanthellae genotypes vary in cell size between 6-15 $\mu \mathrm{m}$ (Fig. 4), with the size of the cell directly correlating to genome size (=DNA content) (LaJeunesse et al., 2005).

The intracellular specific growth rate of the zooxanthellae (i.e. proliferation rate within the host) is estimated by measuring the proportion of algal cells undergoing cytokinesis (mitotic index, $\mathrm{MI}=$ the fraction of cells appearing as doublets) (Wilkerson et al., 1983). Considerable variability exists between the characteristic MI of the different zooxanthellae types. Like other forms of unicellular algae (e.g. diatoms (Geider et al., 1986)) there appears to exist a general size-dependent relationship, with smaller zooxanthellae types corresponding with higher MI (Wilkerson et al., 1988). This size-dependent MI relationship may relate to the cell size dependence of DNA content (LaJeunesse et al., 2005) and/or the cell size dependence of key metabolic rates (Fitt, 1985).
Temperature also impacts upon zooxanthellae MI (Fig. 5a), with the different zooxanthellae types varying in terms of thermal growth optimum (Sakami, 2000; Kinzie et al., 2001; Strychar et al., 2004). Significantly, the thermal growth optimum for many of the zooxanthellae types that associate with corals often exceeds the thermal break-point of the symbiotic association $\left(>32^{\circ} \mathrm{C}\right.$ ) (see e.g. Kinzie et al., 2001; Strychar et al., 2004). Yet, this temperature-dependent ("potential") growth rate can only be obtained when essential nutrients (particularly nitrogen) are not limiting to cell multiplication (Fitt, 2000). Persuasive evidence exists to suggest that under optimal symbiotic conditions the zooxanthellae are nitrogen-limited (Falkowski et al., 1993; Dubinsky and Jokiel, 1994; Cook et al., 1994); thereby limiting potential proliferation rates and ensuring the vitally important transfer of (excess) energy-rich photosynthates to the coral host (see next). 


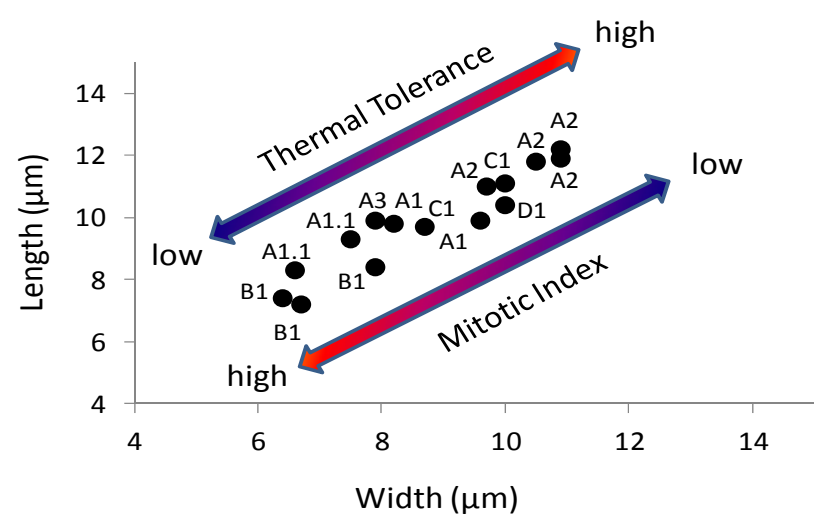

Fig. 4. Size (length and width) of dividing zooxanthellae (after LaJeunesse, 2001; LaJeunesse et al., 2005). Thermal tolerance rankings are based on information summarised within Steinke et al. (2011) and Berkelmans and van Oppen (2006). Mitotic index ranking based on generalised size-dependent relationship (after Wilkerson et al., 1988).

\section{The coral-algae symbiosis: uncoupling photosynthesis from zooxanthellae growth}

Carbon fixation measurements from cultured (nutrientreplete) zooxanthellae provide valuable insight into the importance of MI on the amount of photosynthate potentially available for host transfer. Figure $5 \mathrm{~b}$ demonstrates that the optimum growth efficiency $\left(\sim 20^{\circ} \mathrm{C}\right)$ of this Symbiodinium type (clade E) results in $\sim 80 \%$ of the total daily photosynthetically fixed carbon being retained for cell multiplication. However, at suboptimal growth temperatures (10 and $30^{\circ} \mathrm{C}$ ), growth and photosynthesis become uncoupled such that less than $11 \%$ of daily photosynthetically fixed carbon is utilised for growth; indicating the potential for high host carbon translocation at these temperatures. Unfortunately, no equivalent data exists for the intact coral symbiosis; perhaps reflecting the extreme technical difficulty in obtaining such measurements. Yet, it is known that nutrient-enriched corals that harbour zooxanthellae with elevated MI are typically characterised by lower tissue thickness (McGuire and Szmant, 1997; Cruz-Pinon et al., 2003), reduced gamete production (Tomascik and Sander, 1987; Loya et al., 2004), and lower rates of skeletal accretion (Marubini and Davies, 1996; Ferrier-Pages et al., 2001); all of which are indicative of reduced photosynthate transfer to the host.

The uncoupling of photosynthesis and growth in zooxanthellae is thus predicted to be an essential requirement for the continuous translocation of photosynthates to the coral host, i.e. a stable symbiosis (Dubinsky and Berman-Frank, 2001; Wooldridge, 2010). This condition is most readily achieved in oligotrophic waters that cause zooxanthellae growth rates to be nutrient-limited. In this case, the photosynthetic carbon flux of the zooxanthellae cannot be matched by the cor- responding nitrogen (and phosphorus) fluxes that would be required if the zooxanthellae were to keep the carbon and use it for new cell formation. Because to increase in numbers zooxanthellae have to acquire on the order of one atom of nitrogen for every seven carbon atoms, it follows that any carbon in excess of this ratio will either be expired or translocated to the host (reviewed by Dubinsky and Berman-Frank, 2001). In corals exposed to elevated nutrient levels, the zooxanthellae, instead of acting like a carbon-moving conveyer belt translocating "energy" to the coral hosts, retain seven carbon atoms for every nitrogen atom absorbed from the water (Dubinsky and Berman-Frank, 2001). This results in key changes in the symbiotic association. Less carbon is translocated to the host, the $\mathrm{C}: \mathrm{N}$ ratios in the algae decrease (Muscatine et al., 1989), and the algae are able to use photosynthetically produced carbon skeletons for the synthesis of nitrogencontaining molecules required for cell multiplication, such as amino acids and nucleotides

The host may also contribute to maintaining the zooxanthellae nutrient-limited. Because the zooxanthellae reside with the gastrodermal cells of the coral host, any host process that removes nutrients from the intracellular milieu surrounding the zooxanthellae will act to restrict the diffusive transfer rate (i.e. cellular availability) of nutrients from the external environment. In this regard, the host tissue activity of the nitrogen-assimilating enzyme, glutamine synthetase (GS), appears particularly relevant (Yellowlees et al., 2008; Pernice et al., 2012). Significantly, the efficiency of the GS enzyme is energy (ATP) dependent. This dictates that the effectiveness of the host in maintaining the zooxanthellae growth-limited is modulated via its receipt of photosynthate; as evidenced by the significantly higher GS activity in symbiotic than in aposymbiotic animals (Wang and Douglas, 1998). In this way, any factor that disrupts the flow of photosynthate to the host (e.g. thermal bleaching) may act to release the zooxanthellae from nutrient-limitation, especially in nutrient-enriched waters. This may contribute to the reason why remnant zooxanthellae within semi-bleached hosts typically have low $\mathrm{C}: \mathrm{N}$ ratios that are indicative of nitrogenreplete growth (Cook et al., 1994).

Since both temperature and nutrients interact to codetermine the "realised" rate of zooxanthellae division, it is possible that external nutrient-enrichment need not always be detrimental to the stability of the symbiosis in cooler conditions. In this case, a low thermal (kinetic) constraint on growth, alone, may be sufficient to enforce the transfer of excess photosynthate, even from a nutrient-enlarged zooxanthellae population; thereby benefiting the host in building energy (tissue) reserves. Notably, Muller-Parker et al. (1994) found that DIN (dissolved inorganic nitrogen)-enrichment benefited coral tissue growth during the cool winter months. High levels of DIN have also been found to support coral growth in an aquarium setting where water temperatures remain below $26^{\circ} \mathrm{C}$ (Atkinson et al., 1995). 

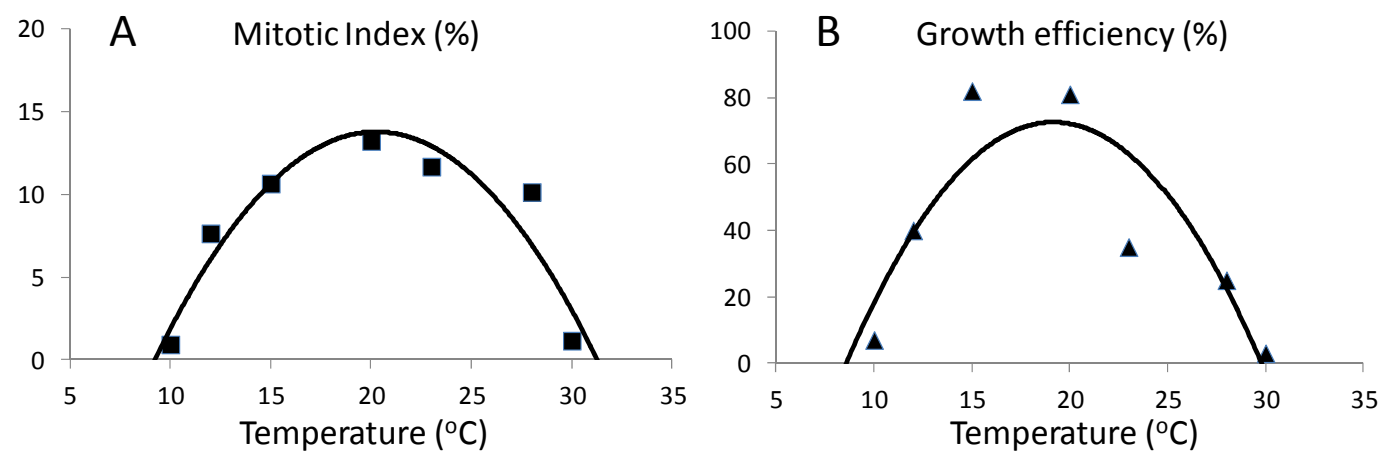

Fig. 5. Symbiodinium californium. (A) MI of Symbiodinium californium (in Clade E) at temperatures ranging from $10^{\circ} \mathrm{C}$ to $30^{\circ} \mathrm{C}$. (B) Corresponding carbon-based growth efficiency, i.e. percentage of daily photosynthetically fixed carbon utilized for growth (adapted from McBride et al., 2009).
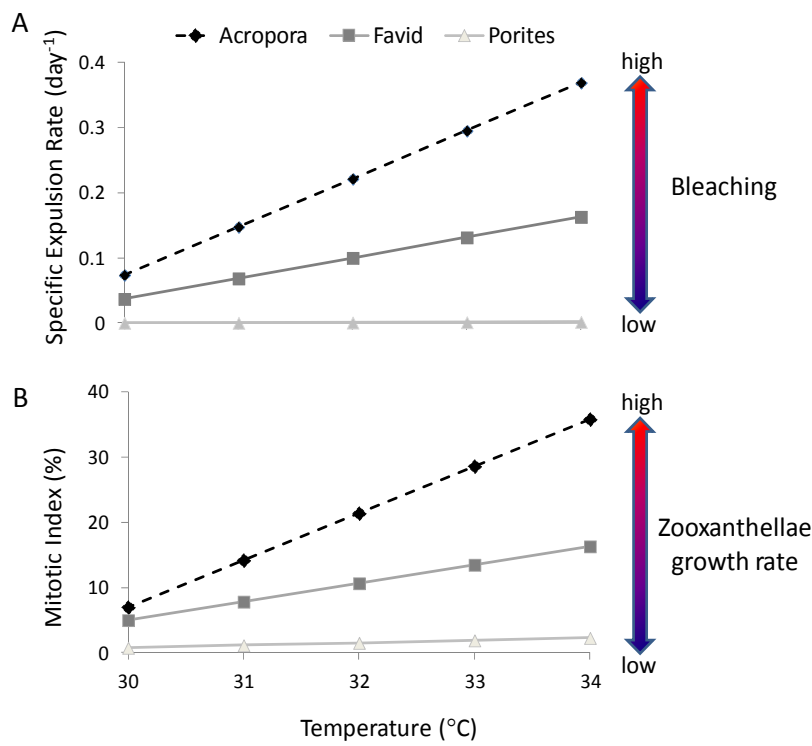

Fig. 6. Acropora hyacinthus, Favites complanata, Porites solida. (A) Zooxanthellae expulsion rates (per day) for the 3 coral species. (B) Corresponding intracellular MI of the zooxanthellae within the 3 coral species (adapted from Strychar et al., 2004).

\section{The coral-algae symbiosis: thermal tolerance coupled to zooxanthellae growth}

As noted earlier, mass coral bleaching is generally recorded when high solar irradiance levels are coupled with sea temperatures that exceed the long-term average by 1$2{ }^{\circ} \mathrm{C}$ for more than a few days-weeks (Berkelmans, 2002). For the cellular bleaching mechanism outlined by Wooldridge (2009a) (Fig. 2b, Fig. 3), the dominant (initial) symbiotic response to the $1-2{ }^{\circ} \mathrm{C}$ temperature excursion is the predicted increase in MI and subsequent expulsion of zooxanthellae that are "stimulated" beyond the crucial growth dynamic (i.e. "autotrophic threshold") wherein the bulk majority of photosynthetically fixed carbon is dedicated to new algal cell growth rather than transferred to the coral host. To date, no experimental study has specifically targeted the impact of zooxanthellae MI on the thermal tolerance of the coral-algae symbiosis. Here, I synthesise the results from a number of related studies, which considered together, provide an initial evidence base in support of a formal (quantitative) linkage.

\subsection{Bleaching thresholds linked to zooxanthellae MI}

Bhagooli and Hidaka (2002) found that the intracellular MI of zooxanthellae within the coral Galaxea fasicularis increased with temperature, and was maximal at the observed bleaching threshold temperature of $30^{\circ} \mathrm{C}$. The authors concluded that, "the host appeared to lose the capacity of controlling algal cell division after 7-day exposure to $30^{\circ} \mathrm{C}$ ". A positive association between rising temperature, zooxanthellae MI, and coral bleaching was also recorded by Strychar et al. (2004) for three different coral families (Acropora hyacinthus, Favites complanata and Porites sol$i d a$ ). Porites solida (massive morphology) was the most thermally tolerant coral, A. hyacinthus (branching/plate morphology) bleached most readily at low temperatures, and F. Complanata (mounding morphology) showed intermediate bleaching tolerance to elevated temperature (Fig. 6a). Notably, the bleaching sensitivity ranking matched the comparative intracellular zooxanthellae MI (Fig. 6b). Grimsditch et al. (2008) also correlated community-level bleaching patterns with intracellular zooxanthellae MI, noting that the bleaching-sensitive branching and plating species consistently had higher MI than the more bleaching-resistant massive species.

The differential expulsion of zooxanthellae with high MI compared with those retained in the symbiosis (Baghdasarian and Muscatine, 2000; Ladriere et al., 2008) supports the deleterious impact of high zooxanthellae MI on the localised stability of the symbiosis during bleaching conditions; and 


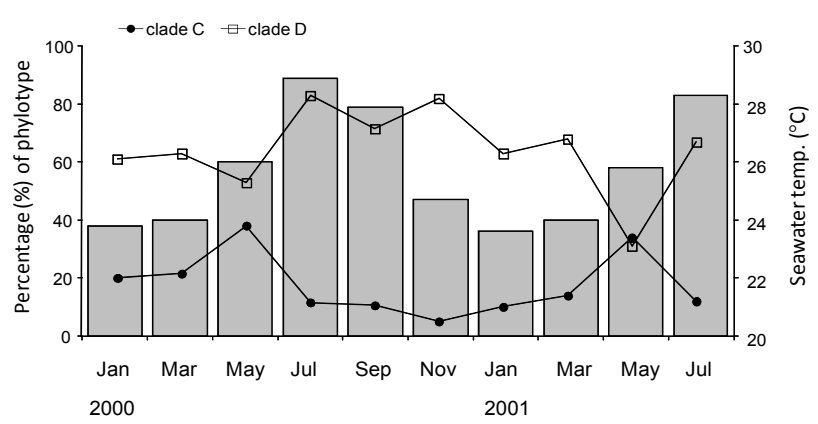

Fig. 7. Acropora palifera. Percentage of clade C and clade D symbionts in relation to seawater temperature and time of year (adapted from Chen et al., 2005).

may underpin the mechanism of symbiont reshuffling (see next). Individual colony bleaching patterns, which typically proceed from the tips or edges towards the base or centre (see e.g. Shenkar et al., 2005), also conform to the known colonyscale topology of MI, wherein the tips and edges consistently contain zooxanthellae with higher MI (Fang and Chen, 1989; Jones and Yellowlees, 1997). Indeed, Wooldridge (2009a) uses the ATP-dependent $\mathrm{CO}_{2}$-limitation model (Fig. 2b, Fig. 3) to argue that the "white tips" on branching corals, and "white edges" on plating corals even outside summer bleaching conditions (Oliver, 1984) may allude to the fact that whole-colony bleaching represents the destructive endpoint to a suite of cellular process that can operate near continuously in nutrient-replete coral symbioses. At these apical colony positions, the low zooxanthellae densities ("bleached tissue") conceals the high levels of zooxanthellae turnover (= high ATP expenditure); as characterised by the cooccurrence of: (i) high zooxanthellae division rates (Fang et al., 1989; Jones and Yellowlees, 1997) with presumed morning peak in MI (Hoegh-Guldberg, 1994), and (ii) high midday expulsion rates (Jones and Yellowlees, 1997; Yamashita et al., 2011).

On this note, it is consistent that reef areas with high nutrient availability (whether due to terrestrial runoff or deep ocean upwelling) are characterised by lower bleaching thresholds and more severe bleaching impacts (D'Croz et al., 2001; Wooldridge, 2009b; Wooldridge and Done, 2009, Wagner et al., 2010). Indeed, a unifying feature from worldwide reef locations that exhibit high $\left(>33^{\circ} \mathrm{C}\right)$ bleaching thresholds is their strongly oligotrophic surface waters during the warm summer months (e.g. Red Sea - no summer river runoff (Genin et al., 1995), western Pacific warm pool - restricted upwelling due to strong thermal stratification (Tomczak and Godfrey, 1994), northern Australia low nutrient loads in summer river runoff (Wooldridge et al., 2006). Recently, an alternative hypothesis has been suggested for why corals exposed to high levels of dissolved inorganic nitrogen (DIN) experience greater bleaching susceptibility compared with corals in low nutrient environ- ments (see Wiedenmann et al., 2012). The proposed mechanism for this link is that high concentrations of DIN lead to high zooxanthellae MI, resulting in an increased demand for all (other) essential plant nutrients by the proliferating endosymbiont population, resulting in a relative under-supply of phosphate. The latter is suggested to lead to altered thylakoid membrane structures with enhanced susceptibility to thermal and light damage (Wiedenmann et al., 2012). Future testing within natural reef settings is required to compare the relative merits of this alternative view with the cellular mechanism proposed here.

The potential importance of additional heterotrophic energy sources that may help to offset autotrophic disruption and thus prolong (maintain) host CCM function deserves consideration. At low to moderate levels of autotrophic disruption, the coral host retains the capacity to utilise stored tissue (e.g. lipid) reserves and/or heterotrophic feeding (see e.g. Grottoli et al., 2006). It is thus reasonable to suggest that the observed beneficial role of host heterotrophic feedings in helping to forestall algal photoinhibition during thermal stress (see e.g. Borell and Bischof, 2008) could result from the prolonged (heterotrophic-assisted) functioning of the active host CCMs. However, apart from those coral species that are particularly well adapted for heterotrophic feeding, continued autotrophic disruption quickly leads to the depletion of tissue energy reserves (Szmant and Gassman, 1990; True, 2005). This fact is consistent with the natural thermal bleaching sequence for a population of massive Porites spp. in which mass expulsion of zooxanthellae only occurred upon depletion of tissue reserves below a common lower threshold (True, 2005). A similar pre-bleaching sequence has also been noted for a branching Acropora spp. (Ainsworth et al., 2008). Indeed, this phenomenon may underpin empirical bleaching relationships that are characterised by specific temperature duration relationships (see e.g. Berkelmans, 2002). In this case, the enhancing impact of temperature on zooxanthellae MI and subsequent declines in autotrophic capacity dictate that as SSTs rise, progressively less time is required before the host's energy storage reserves fall below the level that triggers the onset of bleaching. Intuitively, this effect will be tempered by the amount of storage material maintained by the coral, and may contribute towards the explanation for why thick-tissued corals (e.g. massive Porites spp.) are typically more resistant to thermal stress (Loya et al., 2001). For the extreme and rapid thermal stress that characterises many laboratory experiments, mass zooxanthellae expulsion appears to precede independently of host storage reserves, and may indicate: (i) the inability of the host to quickly mobilise its stored energy reserves; and/or (ii) the concerted action of the coral host to re-allocate the use of its energy stores towards other homeostatic processes. 


\subsection{Zooxanthellae reshuffling driven by preferential expulsion of zooxanthellae with high MI}

The linkage of thermal bleaching thresholds to zooxanthellae MI retains relevance for the "optimal" zooxanthellaetype supported by the symbiosis under different environmental conditions. For locations that experience high summer maximum temperatures, it would clearly be advantageous for the symbiosis to be dominated by zooxanthellae that have a slow growth dynamic. On this note, it is significant that heattolerant clade D1 Symbiodinium have lower MI than heatsensitive clade C2 Symbiodinium (M. J. H. van Oppen, unpubl. data). A trade-off between thermal tolerance and MI has also been noted between three different Symbiodinium types (A6, C9b, C1) within the coral host, Acropora intermedia (Baird et al., 2009). Moreover, by invoking the general size-dependent growth relationship for unicellular algae, it is evident that the linkage between thermal tolerance and zooxanthellae MI may be consistent across a large number of Symbiodinium types (Fig. 4). Indeed, even for zooxanthellae of the same genotype, size differences appear to map against thermal tolerance. For example, Howells et al. (2012) recently demonstrated that for the generalist Symbiodiniumtype $\mathrm{C} 1$, regionally-adapted differences in average cell diameter correlate with altered thermal tolerance; with the isolated population of physically larger $(\sim 10 \%)$ zooxanthellae maintaining greater photochemical performance and survivorship when exposed to an elevated temperature of $32^{\circ} \mathrm{C}$, both in symbiosis and in culture.

For corals that are capable of hosting multiple zooxanthellae types, the differential growth characteristics of the separate types may also underpin the mechanism whereby the relative abundance of the individual types dynamically alters in response to changes in environmental conditions, particularly the temperature regime (Chen et al., 2005; Berkelmans and van Oppen, 2006). In this case, the symbiotic sea anemone Anthopleura elegantissima presents an excellent model system to confirm the details of this "shuffling" mechanism, since it hosts both slow-growing zooxanthellae $(z x)$ and fastgrowing unicellular chlorophyte algae called zoochlorellae (zc) (McCloskey et al., 1996; Saunders and Muller-Parker, 1997). The in hospite growth rate of the smaller $z c$ is $\sim 8$ times faster than the larger $z x$ (Verde and McCloskey, 1996). The relative abundance of $z x$ and $z c$ within A. elegantissima differs along environmental gradients of light and temperature; $z c$ predominating in cool low-light regimes and the $z x$ predominating in warm high-light regimes (Secord and Muller-Parker, 2005). Such reshuffling is predicted by the temperature-dependent growth rates of the $z c$ and $z x$. At cooler temperatures, the superior growth rate of the smaller $z c$ allows them to competitively outgrow $z x$ and dominate the endosymbiont population (Saunders and Muller-Parker, 1997). However, the superior growth rate of $z c$ becomes detrimental when high midday-irradiance levels trigger excessive expulsion (McCloskey et al., 1996) and warm tem- peratures allow fast regrowth of the remnant $z c$ population; this can trigger an exceedence of the "autotrophic threshold", with more carbon per day directed into new cell production than is transferred to the host (Verde and McCloskey, 1996). In this case, the population density of $z c$ decreases relative to the $z x$ population, even though the growth rate of $z c$ is positive - even maximal (Saunders and Muller-Parker, 1997). The preferential loss of symbionts with high MI (McCloskey et al., 1996) confirms the negative selection against fastgrowing symbionts during bleaching conditions, and provides the shuffling mechanism by which slow-growing symbionts opportunistically usurp the role as the dominant competitor.

The opportunistic shuffling between multiple symbiont partners in A. elegantissima appears consistent with the symbiotic functioning of the coral-zooxanthellae symbiosis. For example, the predicted slower growth dynamic of clade D (compared with clade $\mathrm{C}$ symbionts) supports the observations of Chen et al. (2005), who demonstrated dynamic symbiont reshuffling based on seasonal variations in temperature (Fig. 7). In this case, despite a reduction in the overall endosymbiont population size as temperature increases, clade D symbionts progressively dominate the symbiosis, as predicted by the preferential expulsion of the fastergrowing clade $\mathrm{C}$ symbionts. However, the situation is reversed following the recovery of the endosymbiont population into the cooler winter-spring period, with the superior growth dynamic of clade $\mathrm{C}$ symbionts aiding the displacement of slower-growing clade D symbionts. Symbiont reshuffling based on differential growth rates may also explain observed zooxanthellae cell size (diameter) differences between semi-bleached and unbleached colonies of Acropora Formosa (Jones, 1997). Based on the preferential expulsion of smaller zooxanthellae (with assumed higher MI) it is consistent that the average diameter of zooxanthellae in the semi-bleached colonies was $\sim 10-15 \%$ greater than the unbleached colonies.

With this prescribed shuffling mechanism, the coral host can utilise the differential growth rates and competition that exists between zooxanthellae types (Fitt, 1985; Belda-Baillie et al., 2002) to maintain a dynamic symbiont population that is optimally matched to the prevailing conditions, particularly in terms of photosynthate delivery. This can be understood to benefit the coral host by extending the habitat range (i.e. temperature and irradiance conditions) over which it maintains photosynthate receipts from its endosymbiont population; as evidenced by the fact that shuffling from clade $\mathrm{C} 2$ to clade $\mathrm{D} 1$ symbionts facilitates a $1-1.5^{\circ} \mathrm{C}$ increase in the upper thermal bleaching limit of Acropora millepora (Berkelmans and van Oppen, 2006). Here, the raised thermal threshold is predicted to represent the additional (permitted) level of thermal enhancement of clade D1 symbionts before they also exceed their upper "autotrophic threshold" and subsequently become a carbon (energy) sink for the coral host. 


\section{Improving autotrophic carbon budgets for the coral-algae symbiosis}

It is important to emphasise that zooxanthellae proliferation, which ensures that all (suitable) host cell habitat becomes colonised with a photosymbiont in a timely and balanced (roughly 1:1 basis; Muscatine et al., 1998) fashion, is an essential feature of a healthy functioning endosymbiosis, i.e. zooxanthellae growth (per se) is by no means a "resident evil" - as evidenced by the fact that slow proliferation rates can be detrimental to the success of the symbiosis (Fitt, 1985). Thus, speculation within this essay that enhanced zooxanthellae proliferation rates (especially when matched with high expulsion rates) can ultimately cause the endosymbiont population to become a net carbon (energy) sink to the host requires experimental substantiation. Currently, such direct evidence does not exist, and this needs to be addressed with future experimentation. Indirect evidence linking enhanced zooxanthellae proliferation rates with a reduction in host growth/biomass (see, e.g. Cruz-Pinon et al., 2003; Sachs and Wilcox, 2005) can at this stage, only be cited as circumstantial; thus weakening the arguments for the proposed bleaching sequence outlined here. Furthermore, although persuasive evidence exist to suggest that the intracellular zooxanthellae can become $\mathrm{CO}_{2}$-limited under high irradiance conditions (see e.g. Goiran et al., 1996; Crawley et al., 2010), it is important that future experiments specifically target any contributing impact of thermal stress and variable dissolved inorganic carbon concentrations (c.f., Buxton et al., 2009).

Experimentation on the intact symbiosis, although challenging and technically difficult, is a fundamental requirement to improve our understanding in both of these areas of current uncertainty. New and emerging techniques offer great hope for improved experimentation on the intact symbiosis (see e.g. Tremblay et al., 2012). A resignation to experiment on the host or zooxanthellae in isolation will never deliver the necessary energy-budget relations needed to support (or falsify) the integrated coral-algae bleaching model outlined here (Figs. 2b, 3).

\section{Conclusions}

It is not the intention of this essay to cast any doubt on the central importance of the "photoinhibition model" of coral bleaching. Indeed, two decades worth of empirical observation overwhelmingly support the predicted bleaching sequence of algal photoinhibition, oxidative damage and subsequent zooxanthellae expulsion. Rather, this essay has sought to consider whether the photoinhibition bleaching sequence may be a resultant consequence of an earlier breakdown in symbiotic relations, ultimately precipitated by a thermal enhancement of zooxanthellae growth rates and a resultant diminution of host photosynthate transfer; consistent with the understanding that the coral-algae symbiosis is a finely tuned association, based on the "slack" between photosynthetic carbon assimilation and its retention for growth by the symbionts. Indeed, the evidence reviewed in this essay has found strong (circumstantial) support for a link between zooxanthellae growth rates and the setting of upper thermal bleaching limits, but to many, it may be premature to suggest a formal (causal) linkage; most notably because no present experimentation has been undertaken to confirm the host-symbiont carbon (energy) budget relations that underpins such a causal linkage. Notwithstanding this caveat, the predictive consistency of the proposed linkage across multiple scales of observation is compelling, and means that it remains a valid hypothesis. Like all hypotheses, it remains valid only until such time that new experiments/data show it to be falsified (if indeed they can) (Popper, 1959). Future testing and refinement of the ideas presented within this paper thus offers considerable hope for developing further insights into tacking the climate-induced demise of coral-algae symbioses and the reefs they construct.

Acknowledgements. This manuscript benefited from the interactive comments and criticism of Dr Ross Hill (UNSW) and two other anonymous reviewers. A written (archived) record of this peer review, including author responses, is available at: http://www.biogeosciences-discuss.net/9/8111/2012/ bgd-9-8111-2012-discussion.html

Edited by: G. Herndl

\section{References}

Ainsworth, T. D., Hoegh-Guldberg, O., Heron, S. F., Skirving, W. J., and Leggat, W.: Early cellular changes are indicators of prebleaching thermal stress in the coral host, J. Exp. Mar. Biol. Ecol., 364, 63-71, 2008.

Al-Horani, F. A., Al-Moghrabi, S. M., and De Beer, D.: The mechanism of calcification and its relation to photosynthesis and respiration in the scleractinian coral, Galaxea fascicularis, Mar. Biol., 142, 419-426, 2003.

Atkinson, M. J, Carlson, B., and Crow, G. L.: Coral growth in highnutrient, low-pH seawater: A case study of corals cultured at Waikiki Aquarium, Honolulu, Hawaii, Coral Reefs, 14, 215-223, 1995.

Baghdasarian, G. and Muscatine, L.: Preferential expulsion of dividing algal cells as a mechanism for regulating algal-cnidarian symbiosis, Biol. Bull., 199, 278-286, 2000.

Baird, A. H., Bhagooli, R., Nonaka, M., Yakovleva, I., Yamamoto, H. H., Hidaka, M., and Yamasaki, H.: Environmental controls on the establishment of symbiosis in corals, Proc. 11th Int. Coral. Reef. Symp., 2, 108-112, 2009.

Baker, A. C.: Flexibility and specificity in coral-algal symbiosis: diversity, ecology, and biogeography of Symbiodinium, Annu. Rev. Ecol. Evol. Syst., 34, 661-689, 2003. 
Belda-Baillie, C. A., Baillie, B. K., and Maruyama, T.: Specificity of a model cnidarian-dinoflagellate symbiosis, Biol. Bull., 202, 74-85, 2002.

Berkelmans, R.: Time-integrated thermal bleaching thresholds of reefs and their variation on the Great Barrier Reef, Mar. Ecol. Progr. Ser., 229, 73-82, 2002.

Berkelmans, R. and van Oppen, M. J. H.: The role of zooxanthellae in the thermal tolerance of corals: a "nugget of hope" for corals in an era of climate change, Proc. R. Soc. Lond. B., 273, 23052312, 2006.

Bhagooli, R. and Hidaka, M.: Physiological responses of the coral Galaxea fascicularis and its algal symbiont to elevated temperatures, Galaxea, 4, 33-42, 2002.

Bhagooli, R. and Hidaka, M.: Release of zooxanthellae with intact photosynthetic activity by the coral Galaxea fascicularis in response to high temperature stress, Mar. Biol., 145, 329-337, 2004.

Borell, E. M. and Bischof, K.: Feeding sustains photosynthetic quantum yield of a scleractinian coral during thermal stress, Oecologia, 157, 593-601, 2008.

Brown, B. E.: Coral bleaching: causes and consequences, Coral Reefs, 16, s129-s138, 1997.

Buxton, L., Badger, M., and Ralph, P.: Effects of moderate heat stress and dissolved inorganic carbon concentration on photosynthesis and respiration of Symbiodinium Sp. (Dinophyceae) in culture and in symbiosis, J. Phycol., 45, 357-365, 2009.

Buxton, L., Takahashi, S., Hill, R., and Ralph, P. J.: Variability in the primary site of photosynthesis damage in Symbiodinium sp. (Dinophyceae) exposed to thermal stress, J. Phycol., 48, 117126, 2012.

Chen, C. A., Wang, J. T., Fang, L. S., and Yang, Y. W.: Fluctuating algal symbiont communities in Acropora palifera (Scleractinia: Acroporidae) from Taiwan, Mar. Ecol. Progr. Ser., 295, 113-121, 2005.

Cook, C. B, Muller-Parker, G., and Orlandini, C. D.: Ammonium enhancement of dark carbon fixation and nitrogen limitation in zooxanthellae symbiotic with reef corals Madracis mirabilis and Montastrea annularis, Mar. Biol., 118, 157-165, 1994.

Crawley, A., Kline, D. I., Dunn, S., Anthony, K., and Dove, S.: The effect of ocean acidification on symbiont photorespiration and productivity in Acropora Formosa, Global Change Biol., 16, 851-863, 2010.

Cruz-Pinon, G., Carricart-Ganivet, J. P., and Espinoza-Avalos, J.: Monthly skeletal extension rates of the hermatypic coral Montastraea annularis and Montastraea faveolata: biological and environmental controls, Mar. Biol., 143, 491-500, 2003.

D'Croz, L., Mate, J. L., and Oke, J. E.: Responses to elevated sea water temperature and UV radiation in the coral Porites lobata from upwelling and non-upwelling environments on the pacific coast of Panama, Bull. Mar. Sci., 69, 203-214, 2001.

Dubinsky, Z. and Jokiel, P. L.: Ratio of energy and nutrient fluxes regulates symbiosis between zooxanthellae and corals, Pac. Sci., 48, 313-324, 1994.

Dubinsky, Z. and Berman-Frank, I.: Uncoupling primary production from population growth in photosynthesizing organisms in aquatic ecosystems, Aquat. Sci., 63, 4-17, 2001.

Dunn, S. R., Bythell, J. C., Le Tissier, M., Burnett, W., and Thomason, J. C.: Programmed cell death and cell necrosis activity during hyperthermic stress-induced bleaching of the symbiotic sea anemone Aiptasia sp., J. Exp. Mar. Biol. Ecol., 272, 29-53, 2002.

Enriquez, S., Mendez, E. R., and Iglesias-Prieto, R.: Multiple scattering on coral skeletons enhances light absorption by symbiotic algae, Limnol. Oceanogr., 50, 1025-1032, 2005.

Falkowski, P. G., Dubinsky, Z., Muscatine, L., and McCloskey, L.: Population control in symbiotic corals, BioScience, 43, 606-611, 1993.

Fang, L. S., Chen, Y. W., and Chen, C. S.: Why does the white tip of stony coral grow so fast without zooxanthellae?, Mar. Biol., 103, 359-363, 1989.

Ferrier-Pagès, C., Schoelzke, V., Jaubert, J., Muscatine, L., and Hoegh-Guldberg, O.: Response of a scleractinian coral, Stylophora pistillata, to iron and nitrate enrichment, J. Exp. Mar. Biol. Ecol., 259, 249-261, 2001.

Fitt, W. K.: Effect of different strains of zooxanthella Symbiodinium microadriaticum on growth and survival of their coelenterate and molluscan hosts, Proc. 5th Int. Coral Reef Symp., 6, 131-136, 1985.

Fitt, W. K.: Cellular growth of host and symbiont in a cnidarianzooxanthellar symbiosis, Biol. Bull., 198, 110-120, 2000.

Franklin, D. J., Molina Cedrese, C. M., and Hoegh-Guldberg, O.: Increased mortality and photoinhibition in the symbiotic dinoflagellates of the Indo-Pacific coral Stylophora pistillata (Esper) after summer bleaching, Mar. Biol., 149, 633-642, 2006.

Gates, R. D., Baghdasarian, G., and Muscatine, L.: Temperature stress causes host cell detachment in symbiotic cnidarians: implications for coral bleaching, Biol. Bull., 182, 324-332, 1992.

Geider, R. J., Platt, T., and Raven, J. A.: Size dependence of growth and photosynthesis in diatoms: a synthesis, Mar. Ecol. Progr. Ser., 30, 93-104, 1986.

Genin, A., Lazar, B., and Brenner, S.: Vertical mixing and coral death in the Red-Sea following the eruption of mount-Pinatubo, Nature, 377, 507-510, 1995.

Goiran, C., Al-Moghrabi, S., Allemand, D., and Jaubert, J.: Inorganic carbon uptake for photosynthesis by the symbiotic coral/dinoflagellate association. I. Photosynthetic performance of symbionts and dependence on sea water bicarbonate, J. Exp. Mar. Biol. Ecol., 199, 207-225, 1996.

Goulet, D.: Most corals may not change their symbionts, Mar. Ecol. Progr. Ser., 321, 1-7, 2006.

Grimsditch, G., Mwaura, J., Kilonzo, J., Amiyo., N., and Obura, D.: High zooxanthellae densities and turnover correlate with low bleaching tolerance in Kenyan corals, in: Ten Years After Bleaching - Facing the Consequences of Climate Change in the Indian Ocean, CORDIO Status Report 2008, CORDIO, Mombasa Kenya, 235-236, 2008.

Grottoli, A. G., Rodrigues, L. J., and Palardy, J. E.: Heterotrophic plasticity and resilience in bleached corals, Nature, 440, 11861189, 2006.

Hoegh-Guldberg, O.: Population dynamics of symbiotic zooxanthellae in the coral Pocillopora damicornis exposed to elevated ammonium [ $\left.\left(\mathrm{NH}_{4}\right)_{2} \mathrm{SO}_{4}\right]$ concentrations, Pac. Sci., 48, 263272, 1994.

Howells, E. J., Beltran, V. H., Larsen, N. W., Bay, L. K., Willis, B. L., and van Oppen, M. J. H.: Coral thermal tolerance shaped by local adaptation of photosymbionts, Nature Clim. Change, 2, 116-120, 2012.

Jones, R. J.: Changes in zooxanthellar densities and chlorophyll concentrations in corals during and after a bleaching event, Mar. 
Ecol. Progr. Ser., 159, 51-59, 1997.

Jones, R. J. and Yellowlees, D. I.: Regulation and control of intracellular algae (=zooxanthellae) in hard corals, Phil. Trans. Roy. Soc. Lond. B. Biol. Sci., 352, 457-468, 1997.

Jones, R. J. and Hoegh-Guldberg, O.: Diurnal changes in the photochemical efficiency of the symbiotic dinoflagellates (Dinophyceae) of corals: photoprotection, photoinactivation and the relationship to coral bleaching, Plant. Cell Environ., 24, 89-99, 2001.

Jones, R. J., Hoegh-Guldberg, O., Larkum, A. W. D., and Schreiber, U.: Temperature-induced bleaching of corals begins with impairment of the $\mathrm{CO}_{2}$ fixation mechanism in zooxanthellae, Plant. Cell Environ., 21, 1219-1230, 1998.

Kinzie, R. A, Takayama, M., Santos, S. R., and Coffroth, M. A.: The adaptive bleaching hypothesis: experimental tests of critical assumptions, Biol. Bull., 200, 51-58, 2001.

Koike, K., Jimbo, M., Sakai, R., Kaeriyama, M., Muramoto, K., Ogata, T., Maruyama, T., and Kamiya, H.: Octocoral chemical signalling selects and controls dinoflagellate symbonts, Biol. Bull., 207, 80-86, 2004.

Ladriere, O., Compere, P., Decloux, N., Vandewalle, P., and Poulicek, M.: Morphological alterations of zooxanthellae in bleached cnidarian hosts, Cah. Biol. Mar., 49, 215-227, 2008.

LaJeunesse, T. C.: Investigating the biodiversity, ecology, and phylogeny of endosymbiotic dinoflagellates in the genus Symbiodinium using the ITS region: in search of a "species" level marker, J. Phycol., 37, 866-880, 2001.

LaJeunesse, T. C., Lambert, G., Andersen, R. A., Coffroth M.A., and Galbraith, D. W.: Symbiodinium (Pyrrhophyta) genomes sizes (DNA content) are smallest among dinoflagellates, J. Phycol., 41, 880-886, 2005.

Lesser, M. P.: Exposure of symbiotic dinoflagellates to elevated temperatures and ultraviolet radiation causes oxidative stress and inhibits photosynthesis, Limnol. Oceanogr., 41, 271-283, 1996.

Loya, Y., Sakai, K., Yamazato, K., Nakano, Y., Sambali, H., and van Woesik, R.: Coral bleaching: the winners and the losers, Ecol. Lett., 4, 122-131, 2001.

Loya, Y., Lubinevsky, H., Rosenfeld, M., and Kramarsky-Winter, E.: Nutrient enrichment caused by in situ fish farms at Eilat, Red Sea is detrimental to coral reproduction, Mar. Poll. Bull., 49, 344-353, 2004.

Marubini, F. and Davies, P. S.: Nitrate increases zooxanthellae population density and reduces skeletogenesis in corals, Mar. Biol., 127, 319-328, 1996.

McBride, B. B., Muller-Parker, G., and Jakobsen, H. H.: Low thermal limit of growth rate of Symbiodinium californium (Dinophyta) in culture may restrict the symbiont to southern populations of its host anemones (Anthopleura spp.; Anthozoa, Cnidaria), J. Phycol., 45, 855-863, 2009.

McCloskey, L. R., Cove, T. G., and Verde, E. A.: Symbiont expulsion from the anemone Anthopleura elegantissima (Brandt) (Cnidaria; Anthozoa), J. Exp. Mar. Biol. Ecol., 195, 173-186, 1996.

McGuire, M. P. and Szmant, A. M.: Time course of physiological responses to $\mathrm{NH}_{4}$ enrichment by a coral-zooxanthellae symbiosis, Proc. 8th Int. Coral Reef Symp., 1, 909-914, 1997.

Muller-Parker, G., McCloskey, L. R., Hoegh-Guldberg, O., and McAuley, P. J.: Effect of ammonium enrichment on animal and algal biomass of the coral Pocillopora damicornis, Pac. Sci., 48,
234-283, 1994.

Muscatine, L., Falkowski, P. G., Dubinsky, Z., Cook, P. A., and McCloskey, L. R.: The effect of external nutrient resources on the population dynamics of zooxanthellae in a reef coral, Proc. Roy. Soc. Lond. Ser. B., 236, 311-324, 1989.

Muscatine, L., Ferrier-Pages, C., Blackburn, A., Gates, R. D., Baghdasarian, G., and Allemand, D.: Cell-specific density of symbiotic dinoflagellates in tropical anthozoans, Coral Reefs, 17, 329337, 1998.

Oliver, J. K.: Intra-colony variation in the growth of Acropora formosa: extension rates and skeletal structure of white (zooxanthellae-free) and brown-tipped branches, Coral Reefs, 3, 139-147, 1984.

Pernice, M., Meibom, A., Van Den Heuvel, A., Kopp, C., DomartCoulon, I., Hoegh-Gulberg, O., and Dove, S.: A single-cell view of ammonium assimilation in coral-dinoflagellate symbiosis, ISME J., 6, 1314-1324, 2012.

Popper, K. R.: The logic of scientific discovery, Routledge, London, 1959.

Ralph, P. J., Gademann, R., and Larkum, A. W. D.: Zooxanthellae expelled from bleached corals at $33^{\circ} \mathrm{C}$ are photosynthetically competent, Mar. Ecol. Progr. Ser., 220, 163-168, 2001.

Rowan, R.: Coral bleaching: thermal adaptation in reef coral symbionts, Nature, 430, 742, 2004.

Sachs, J. L. and Wilcox, T. P.: A shift to parasitism in the jellyfish symbiont Symbiodinium microadriaticum, Proc. R. Soc. London Ser. B, 273, 425-429, 2006.

Sakami, T.: Effect of temperature, irradiance, salinity and inorganic nitrogen concentration on coral zooxanthellae in culture, Fisheries Sci., 66, 1006-1013, 2000.

Saunders, B. K. and Muller-Parker, G.: The effects of temperature and light on two algal populations in the temperate sea anemone Anthopleura elegantissima (Brandt, 1835), J. Exp. Mar. Biol. Ecol., 211, 213-224, 1997.

Secord, D. and Muller-Parker, G.: Symbiont distribution along a light gradient within an intertidal cave, Limnol. Oceanogr., 50, 272-278, 2005.

Shenkar, N., Fine, M., and Loya, Y.: Size matters: bleaching dynamics of the coral Oculina Patagonica, Mar. Ecol. Progr. Ser., 94, 181-188, 2005.

Smith, D. J., Suggett, D. J., and Baker, N.: Is photoinhibition of zooxanthellae photosynthesis the primary cause of thermal bleaching in corals?, Global Change Biol., 11, 1-11, 2005.

Stanley, G. D.: Photosymbiosis and the evolution of modern coral reefs, Science, 312, 857-858, 2006.

Stat, M., Carter, D., and Hoegh-Guldberg, O.: The evolutionary history of Symbiodinium and scleractinian hosts - Symbiosis, diversity, and the effect of climate change, Perspect. Plant Ecol. Evol. Syst., 8, 23-43, 2006.

Steinke, M., Brading, P., Kerrison, P., Warner, M. E., and Suggett, D. J.: Concentrations of dimethylsulfoniopropionate and dimethyl sulphide are strain-specific in symbiotic dinoflagellates (Symbiodinium sp., Dinophyceae), J. Phycol., 47, 775-783, 2011.

Strychar, K. B., Coates, M., and Sammarco, P. W.: Loss of Symbiodinium from bleached Australian scleractinian corals (Acropora hyacinthus, Favites complanata and Porites solida), Mar. Fresh. Res., 55, 135-144, 2004. 
Szmant, A. M. and Gassman, N. J.: The effects of prolonged 'bleaching' on the tissue biomass and reproduction of the reef coral Montastraea annularis, Coral Reefs, 8, 217-224, 1990.

Takahashi, S. and Murata, N.: Glycerate-3-phosphate, produced by $\mathrm{CO}_{2}$ fixation in the Calvin cycle, is critical for the synthesis of the D1 protein of photosystem II, Biochim. Biophys. Ac., 1757, 198-205, 2006.

Tang, E. P. Y.: Why do dinoflagellates have lower growth rates, J. Phycol., 32, 80-84, 1996.

Tomczak, M. and Godfrey, M.: Regional Oceanography: an Introduction, Pergamon, Oxford, 422 pp., 1994.

Tomascik, T. and Sander, F.: Effects of eutrophication on reefbuilding corals. III. Reproduction of the reef building coral Porites porites, Mar. Biol., 94, 77-94, 1987.

Tremblay, P., Grover, R., Maguer, J. F., Legendre, L., and FerrierPagès, C.: Autotrophic carbon budget in coral tissue: a new ${ }^{13} \mathrm{C}$ based model of photosynthate translocation, J. Exp. Biol., 215, 1384-1393, 2012.

Trench, R. K.: Microalgal-invertebrate symbioses: a review, Endocytobiosis Cell Res., 9, 135-175, 1993.

True, J. D.: Massive Porites corals as indicators of environmental change, PhD Thesis, James Cook Uni., Australia, 2005.

Verde, A. E. and McCloskey, L. R.: Photosynthesis and respiration of two species of algae symbionts in the Anemone Anthopleura elegantissima (Brandt) (Cnidaria; Anthozoa), J. Exp. Mar. Biol. Ecol., 195, 187-202, 1996.

Veron, J. E. N.: Corals in space and time: the biogeography and evolution of the scleractinians, Cornell Univ. Press, Ithaca, New York, 1995.

Wagner, D. E, Kramer, P., and van Woesik, R.: Species composition, habitat, and water quality influence coral bleaching in southeastern Florida, Mar. Ecol. Progr. Ser., 408, 65-78, 2010.

Wang, J. T. and Douglas, A. E.: Nitrogen recycling or nitrogen conservation in an algae-invertebrate symbiosis?, J. Exp. Biol., 201, 2445-2453, 1998.

Warner, M. E., Fitt, W. K., and Schmidt, G. W.: Damage to photosystem II in symbiotic dinoflagellates: a determinant of coral bleaching, Proc. Nat. Acad. Sci. USA, 96, 8007-8012, 1999.
Wiedenmann, J., D’Angelo, C., Smith, E. G., Hunt, A. N., Legiret F.-E., Postle, A. D., and Achterberg, E. P.: Nutrient enrichment can increase the susceptibility of reef corals to bleaching, Nature Climate Change, 3, 160-164, doi:10.1038/nclimate1661, 2012.

Wilkerson, F. P., Muller-Parker, G., and Muscatine, L: Temporal patterns of cell division in natural populations of endosymbiont algae, Limnol. Oceanogr., 28, 1009-1014, 1983.

Wilkerson, F. P. D., Kobayashi, D., and Muscatine, L.: Mitotic index and size of symbiotic algae in Caribbean reef corals, Coral Reefs, 7, 29-36, 1988.

Wong, J. T. Y. and Kwok, A. C. M.: Proliferation of dinoflagellates: blooming or bleaching, BioEssays, 27, 730-740, 2005.

Wooldridge, S. A.: A new conceptual model for the warm-water breakdown of the coral-algae endosymbiosis, Mar. Fresh. Res., 60, 483-496, 2009a.

Wooldridge, S. A.: Water quality and coral bleaching thresholds: Formalising the linkage for the inshore reefs of the Great Barrier Reef, Australia, Mar. Poll. Bull., 58, 745-751, 2009b.

Wooldridge, S. A.: Is the coral-algae symbiosis really mutuallybeneficial for the partners? BioEssays, 32, 615-625, 2010.

Wooldridge, S. A. and Done, T. J.: Improved water quality can ameliorate effects of climate change on corals, Ecol. App., 19, 14921499, 2009.

Wooldridge, S. A., Brodie, J. A., and Furnas, M.: Exposure of innershelf reefs to nutrient enriched runoff entering the Great Barrier Reef Lagoon: Post-European changes and the design of water quality targets, Mar. Poll. Bull., 52, 1467-1479, 2006.

Yamashita, H., Suzuki, G., and Hayashibara, T.: Do corals select zooxanthellae by alternative discharge?, Mar. Biol., 158, 87-100, 2011.

Yellowlees, D., Rees, T. A., and Leggat, W.: Metabolic interactions between algal symbionts and invertebrate hosts, Plant. Cell. Environ., 31, 679-694, 2008. 